


\title{
Molekulare Matrizen
}

\author{
II. Proteine
}

mit 323 Abbildungen

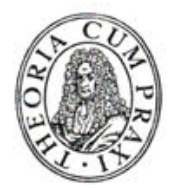

AKADEMIE-VERLAG - BERLIN 1978 
Erschienen im Akademie-Verlag, 108 Berlin, Leipziger Straße 3-4 (C) Akademie-Verlag Berlin 1978

Lizenznummer: $202 \cdot 100 / 510 / 78$

Einband und Schutzumschlag: Rolf Kunze

Gesamtherstellung: VEB Druckhaus „Maxim Gorki“, 74 Altenburg

Bestellnummer: $7622376(2148 / 11 / 2)$. LSV 1315

Printed in GDR

DDR $42,-M$ 